\title{
Correction to: Trend estimation for complex survey designs of water chemistry indicators from Sierra Nevada Lakes
}

\author{
L. A. H. Starcevich (iD) - T. McDonald • \\ A. Chung-MacCoubrey • A. Heard • J. Nesmith • \\ T. Philippi
}

Published online: 22 October 2018

C) Springer Nature Switzerland AG 2018

\section{Correction to: Environ Monit Assess (October 2018) 190:596 https://doi.org/10.1007/s10661-018-6963-1}

The original version of this article contained a misaligned equation. The following equation replaces the online printed on the 5th page of the article.

In our simulation, we considered detecting trend in the mean of a resource. We computed a design-based estimate of the mean in year $j$ using the a Horvitz-Thompson estimator (Horvitz and Thompson 1952, Cordy 1993):

$\hat{\mu}_{j}=\stackrel{\sum_{i=1}^{n_{j}} \frac{y_{i j}}{\pi_{i j}} / \sum_{i=1}^{n_{j}} \frac{1}{\pi_{i j}}}{ }$

where $n_{j}$ is the sample size in year $j$, and is the inclusion probability evaluated at site $i$ during year $j$.

L. A. H. Starcevich $(\bowtie) \cdot$ T. McDonald

Western EcoSystems Technology, Inc., 2725 NW Walnut Blvd., Corvallis 97330, USA

e-mail: 1starcevich@west-inc.com

A. Chung-MacCoubrey

National Park Service Inventory and Monitoring Program,

Klamath Network, 1250 Siskiyou Blvd, Ashland, OR 97520, USA

\author{
A. Heard · J. Nesmith \\ National Park Service Inventory and Monitoring Program, Sierra \\ Nevada Network, 47050 Generals Highway, Three Rivers, CA \\ 93271, USA \\ T. Philippi \\ National Park Service Inventory and Monitoring Division, c/o \\ Cabrillo National Monument, 1800 Cabrillo Memorial Dr., San \\ Diego, CA 92106, USA
}

